\title{
Production and characterization of exopolysaccharide from marine Bacillus sp. MSHN2016 with studying its effect on isoniazid/ rifampicin-induced hepatic and renal toxicities in rats
}

\author{
Manal S. Selim* ${ }^{1 *}$, Sahar S. Mohamed ${ }^{1}$, Mohsen M. Asker ${ }^{1}$, Abeer A.A. Salama², Heba M.I Abdallah², Noha N. Yassen ${ }^{3}$ \\ ${ }^{1}$ Microbial Biotechnology Department, Genetic Engineering and Biotechnology Research Division, National Research Centre, Dokki, Cairo, Egypt. \\ ${ }^{2}$ Pharmacology Department, Medical Division, National Research Centre, Dokki, Cairo, Egypt. \\ ${ }^{3}$ Pathology Department, Medical Division, National Research Centre, Dokki, Cairo, Egypt.
}

\section{ARTICLE INFO \\ Article history: \\ Received on: 24/04/2018 \\ Accepted on: 05/07/2018 \\ Available online: $31 / 08 / 2018$}

Key words:

Exopolysaccharide, Bacillus

sp., isoniazid/rifampicin,

hepatic and renal toxicity.

\begin{abstract}
Exopolysaccharides (EPSs) are bioactive natural products used in different applications. A preliminary chemical analysis of EPSMSHN indicated that the monosaccharides were arabinose, xylose, glucose and glucuronic acid with a relative ratio of 1: 1: $2: 1$, respectively, with a weight average molecular weight $(M w)$ of $5.50 \times 10^{5} \mathrm{~g} / \mathrm{mol}$ and a number average molecular weight $(\mathrm{Mn})$ of $3.45 \times 10^{5} \mathrm{~g} / \mathrm{mol}$. INH/RIF deteriorated hepatic and renal functions through decreased hepatic and renal GSH and increasing MDA contents that associated with hepatocellular apoptosis as well as degeneration and fibrosis in many tubules. The treatment with EPSMSHN at different doses (50 and $100 \mathrm{mg} / \mathrm{kg})$ corrected all previously mentioned INH/RFP-induced changes. In conclusion, EPSMSHN at both doses protected from the hepatic and renal toxicity induced by INH/RFP through its antioxidant and antifibrotic influence.
\end{abstract}

\section{INTRODUCTION}

One of the reasons of $50 \%$ of the cases of acute liver failure is drug-induced hepatic toxicity which mimics all forms of liver disease (Kaplowitz, 2001). Distinctive sorts of pills, for example, acetaminophen, chloroquine also isoniazid are inducers for that hepatotoxicity over the globe. Isoniazid moreover rifampicin, the initial drugs utilized for tuberculosis help, are connected with hepatotoxicity (Kaplowitz, 2004). Those rate of hepatotoxicity needs to be been appeared to being substantially higher for creating nations such as India (8-30\%) contrasted with that for propelled nations (Sharma, 2004). Toxic liver injury happens in greatest amount comparing with the other organs, because the liver is a presentable organ for absorbed substances

\section{${ }^{*}$ Corresponding Author}

Manal S. Selim, Microbial Biotechnology Department, Genetic Engineering and Biotechnology Research Division, National Research Centre,Dokki, Cairo,Egypt.E-mail:manalsleem@yahoo.com and their metabolism and disposal (Kaplowitz, 2001). A major mechanism evolved in INH and RFP-induced hepatic toxicity is endogenous lipids peroxidation. This mechanism is may be because of the creation of the exceedingly reactive oxygen species (ROS) provokes the destruction of the cell membrane (Sharma, 2004). Many different mechanisms cause hepatorenal toxicity, including cellular membrane disruption and cell death and creation of new adducts from binding between cell proteins and the drug resulting in an immunologic reaction (Robin et al., 1997). Other reasons included as drug metabolism interruption (Yun et al., 1993), actin filaments disruption leading to abnormal bile flow and cholestasis and jaundice (Trauner et al., 1998), induction of pathways of Fas and tumor necrosis factor (TNF) (Reed, 2001), also ROS accumulation due to inhibition of mitochondrial dysfunction (Pessayre et al., 2001). INH and RFP caused instinctive sorts of hepatic metabolic aberrations because the liver is the major site for detoxifying these anti-tubercular drugs (Sharma, 2004). Expanding confirmation recommends that harmful metabolites potentiate oxidative stress reaction in the rats' liver (Saad et 
al., 2010; Chen et al., 2012). It was recorded that INH oxidized by itself to a reactive metabolite that binds to hepatic proteins mediating immune liver injury (Yamamoto et al., 2005). EPSs are high molecular weight polymers composed of homo- or heterocarbohydrates. They are produced by a different microorganism such as bacteria, fungi and yeasts, where they are secreted by these microorganisms to the external environment (Selim et al., 2018). It was known that EPSs are bioactive natural products used in different applications such as medical, the biochemical also pharmacological application as a result of their specific biological activities (Ye et al., 2012; Selim et al., 2018).

In the present study, a heterogeneous exopolysaccharide will be obtained and identified from bacterial isolate. The chemical characteristics of EPS will be determined while the hepatic and renal toxicity will be induced by INH/RFP and this model will be used to reveal the protective effect of bacterial EPS.

\section{MATERIALS AND METHODS}

\section{Animals}

Male Sprague-Dawley rats weighing 150-200 g were housed in the animal house, pharmacology department, National Research Centre Experimental protocol was approved (Number: 16-438) and met the Guidelines for Animal Experimentation of the Ethical Committee of the National Research Centre which gave its consent in accordance with the National Regulations on Animal Welfare and Institutional Animal Ethical Committee (IAEC).

\section{Chemicals, Drugs and Diagnostic Kits}

All chemicals used in casein hydrolysate glucose broth medium, chemical analysis of EPS and DPPH (2,2-diphenyl-1picrylhydrazyl) were obtained from Sigma, USA. Other chemicals and their sources were: paracetamol was obtained from (EIPICO, Egypt), silymarin (SEDICO, Egypt) and isoniazid/rifampicin (Sandoz Pharmaceutical Co., Germany). Diagnostic kits for ALT (alanine aminotransferase) and AST (aspartate aminotransferase) were obtained from Biodiagnostic Co., Egypt.

\section{Methods}

\section{Isolation of bacteria}

The serial dilution method was applied for isolation of bacteria, the sample (sediment of the shore of Ageeba beach (the Mediterranean Sea, Marsa Matrooh governorate) was diluted to $10^{-6}$ and plated on marine nutrient agar medium (Hayakawa and Nonomura, 1987) then incubated at $37^{\circ} \mathrm{C}$ for $48 \mathrm{~h}$. Smooth, ropy and mucous colonies from each plate were selected.

\section{Production and isolation of exopolysaccharide (EPS) from liquid culture}

Pure colonies were screened for EPS production by inoculation $\left(10^{7} / \mathrm{mL}\right)$ of cells into $250 \mathrm{~mL}$ Erlenmeyer flasks containing $50 \mathrm{~mL}$ of casein hydrolysate glucose broth (Al-Nahas et al., 2011) consisting of (g/L): Casein hydrolysate 2.5; $\mathrm{K}_{2} \mathrm{HPO}_{4}$ $4.0 ; \mathrm{MgSO}_{4} .7 \mathrm{H}_{2} \mathrm{O} 0.7 ; \mathrm{MnSO}_{4} .7 \mathrm{H}_{2} \mathrm{O} 0.05$; and glucose 30.0 , dissolved in $75 \%$ seawater, $\mathrm{pH} 7.0$. The fermentation cultures were incubated at $37^{\circ} \mathrm{C}$ under shaking at $120 \mathrm{rpm}$ for 3 days. The culture medium was centrifuged at $5000 \mathrm{rpm}$ for $10 \mathrm{~min}$
(Sigma-Laborzentrifugen, 2K15) to remove bacterial cells. Trichloroacetic acid (5\%) was added and left overnight at $4^{\circ} \mathrm{C}$ and centrifuged at $5000 \mathrm{rpm}$ again. The $\mathrm{pH}$ of the clear solution was adjusted to 7.0 with $\mathrm{NaOH}(0.1 \mathrm{M})$ solution and dialyzed three times against distilled water using dialysis tubing (MWCO 2000). The supernatant was completed in four volumes with ethanol $95 \%$ and left overnight at $4^{\circ} \mathrm{C}$. The precipitated EPS were separated by centrifugation at $5000 \mathrm{rpm}$, for $15 \mathrm{~min}$, redissolved in distilled water, dialyzed with distilled water and fractionation by precipitation using 1, 2, 3 and 4 volumes of chilled absolute ethanol collected, washed by acetone, diethyl ether and dried at $60^{\circ} \mathrm{C}$ until constant weight (Shene et al., 2008), the main fraction was designated as EPSMSHN.

\section{Identification of bacteria}

Strain number 5, which produces elevated EPS levels, was identified on the basis of morphological, physiological, and biochemical characteristics (Cappuccino and Sherman, 2004) combined with $16 \mathrm{~S}$ rRNA sequence analysis. The universal primers delineated by Weisburg et al. (1991) particularly ITS1 (5'-TCCGTAGGTGAACTTTGCG G-3') and ITS4 (5'-TCCTCCGCTTATTGATATGC-3'), were used to amplify the $16 \mathrm{~S}$ rRNA gene sequence. A single, discrete, polymerase chain reaction amplicon was resolved on agarose. Sequencing products were resolved on an Applied Biosystems (Foster City, CA, USA) model $3730 \mathrm{XL}$, automated DNA sequencing system. Data were submitted to GenBank and the sequence compared with the GenBank database (http://www.ncbi.nlm.nih.gov) using BLAST (Tamur et al., 2007).

\section{Chemical analysis}

Sulfate was determined using the turbidly method (Dodgson and Price, 1962). Uronic acids were determined at 525 $\mathrm{nm}$ by the m-hydroxybiphenyl colorimetric method (FilisettiCozzi and Corpita, 1991). The monosaccharide composition was determined by HPLC on shim pack SCR-101N column (Shimadzu) with water deionized as the mobile phase at $0.5 \mathrm{~mL} /$ min (Sudhamani et al., 2004; El-Sayed, et al., 2005).

\section{Fourier-transform infra-red (FT-IR)}

The FT-IR of the EPS was measured on a Bucker scientific 500-IR Spectrophotometer (Billerica, MA, USA). The sample was mixed with $\mathrm{KBr}$ powder, ground and pressed into a 1 mm pellets for FTIR measurements in the range of $400-4000 \mathrm{~cm}^{-1}$ (Ray, 2006).

\section{Determination of the molecular weight of EPS}

The molecular weight of EPS was determined to an Agilent 1100 HPLC with a refractive index detector (RID), Water Company Ireland according to Jun et al. (2006). The polydispersity index $(P I)$ calculated from the $M w / M n$ magnitude relation (You et al., 2013).

\section{In-vitro antioxidant activity using DPPH}

Free radical scavenging activity was measured against 1,1-diphenyl-2 picrylhydrazyl (DPPH) radicals using the method of Asker and Shawky (2010). DPPH ethanol solution $(5 \mathrm{~mL}$, freshly prepared) was added to $1 \mathrm{~mL}$ of EPS solution with deferent 
concentrations $(30-200 \mu \mathrm{g} / \mathrm{mL})$ in water. Solutions were mixed vigorously and incubated at room temperature in the dark for 60 min. Supernatant absorbance was measured at $517 \mathrm{~nm}$. A lower absorbance indicates higher free radical scavenging activity, as determined by graphing inhibition percentage plotted against compound concentration. All experiments were carried out in triplicate and averaged.

The scavenging activity was calculated as follows:

$$
\begin{aligned}
& \text { Scavenging ability }(\%)=\left(\mathrm{A}_{517} \text { of control }-\mathrm{A}_{517}\right. \text { of } \\
& \text { sample/ } \left.\mathrm{A}_{517} \text { of control }\right) \times 100 \text {. }
\end{aligned}
$$

The $\mathrm{EC}_{50}$ value is the effective concentration of EPSMSHN at which the DPPH radicals were scavenged by $50 \%$.

\section{Acute toxicity study}

EPS was dissolved in distilled water then given orally to rats of both sex in graded doses up $4 \mathrm{~g} / \mathrm{kg}$. The control group received the same volumes of distilled water. The percentage mortality was recorded 24 hours later. Observation of rats for 14 days, for any changes in the skin and fur, respiratory, circulatory, autonomic, central nervous systems, somatomotor activity and behavior pattern (Desoukey et al., 2016).

\section{Studying the hepatoprotective effects of EPS}

\section{Experimental design}

The animals were randomly allocated into 5 groups $(6$ rats in each), and treated as follow: Group I, the negative control, received $10 \mathrm{ml} / \mathrm{kg}$ of normal saline/day; group II, the positive control, received i.p. daily injection of isoniazid/rifampicin (INH/ RIF) formulation at a dose of 50/100 mg/kg (Shih et al., 2013), respectively; group III, received oral doses of silymarin, the standard hepatoprotective drug (50 mg/kg/day), with the daily doses of INH/RIF as in group II; group IV and V treated with the investigated polysaccharide, administered orally by gavages tube at doses of 50 and $100 \mathrm{mg} / \mathrm{kg}$, with the daily doses of INH/ RIF as in group II. All treatments lasted for 28 days. After $24 \mathrm{~h}$ last drug administration, the animals were sacrificed and blood samples were obtained from the retro-orbital plexus in a plain tube. Samples were left to clot and centrifuged for 5 minutes at $5000 \mathrm{x}$ g using a cooling centrifuge (Sigma and Laborzentrifugen, $2 \mathrm{k} 15$, Germany) to obtain the serum.

\section{Biochemical analysis}

\section{Liver and kidney related parameters}

Aspartate transaminase (AST), alanine transaminase (ALT), total, direct bilirubin serum creatinine and blood urea nitrogen (BUN) were measured in serum.

\section{Oxidative stress biomarkers}

Tissue samples of liver and kidney were quickly homogenized for determination of lipid peroxides (Ohkawa et al., $1979)$ and reduced glutathione (GSH) (Ellman, 1959) contents.

\section{Histopathological study}

The kidneys and livers were harvested from the sacrificed rats after dissection, fixed in $10 \%$ buffered formalin ( $\mathrm{pH} 7.4$ ). The fixed specimens were sliced, processed, and embedded into paraffin blocks. The blocks were cut into $4 \mu \mathrm{m}$ paraffin sections by a rotator microtome. The section was stained with Hematoxylin and Eosin (H\&E) and with Van Gieson stains (Bancroft and Gamble, 2008).

\section{Morphometric measurements}

\section{Detection of fibrotic area}

The morphometric analysis was carried out on Van Gieson stained slides. This area was determined as an area per field in micrometer square. The results appeared automatically on the monitor in the form of a table with the total, mean, standard deviation, standard error, the minimum area and the maximum area was measured. The area of fibrosis measured in 10 fields in each slide.

\section{Counting of the inflammatory cells}

The morphometric analysis was carried out on $\mathrm{H}$ and E stained slides. First, detection and counting of the target cells (inflammatory cells) were performed. The average of counted inflammatory cells was determined by counting in 10 fields in each slide. The morphometric analysis was performed at the Pathology Department, National Research Center using the Leica Qwin 500 Image Analyzer (LEICA Imaging Systems Ltd, Cambridge, England,) which consists of Leica DM-LB microscope with JVC color video camera attached to a computer system Leica Q 500IW.

\section{Statistical analysis}

All the results were expressed as mean \pm SEM (standard error of the mean). Analyses were processed using Graph Pad Prism software for Windows (version 6.0, Graph Pad Software, Inc., San Diego, CA). The significance of difference among the studied groups was determined using one-way analysis of variance (ANOVA) followed by Tukey post-hoc test. Values with $\mathrm{P}<0.05$ were considered significant. Statistical analysis for histopathological studies was performed using SPSS statistical software, version 15.0 (SPSS Inc., Chicago, IL, USA) for Windows.

\section{RESULTS}

\section{Isolation, screening, and identification of the EPS-producing} bacteria

Eighteen isolates have been isolated from the sediment of the shore of Ageeba beach (MarsaMatrooh governorate), nine isolates only produced EPS. Strain number five was selected for further studied due to its highest production of EPS $(8.25 \mathrm{~g} / \mathrm{L})$. The strain showed mucous appearance on solid medium, aerobic, Gram-positive, motile, spore-forming, halophilic, catalase and oxidase positive. The partial $16 \mathrm{~S}$ rDNA sequence was resolved and contrasted with the GenBank databases in the National Center for Biotechnology Information (NCBI) (http://www.ncbi.nlm. nih.gov) using the BLASTN 2.2.6 program. It was found that the promising isolate was associated with genus Bacillus sp. with $97 \%$ similarity as represented in the phylogenetic tree analysis. So it was identified as Bacillus sp. MSHN2016. The sequences were submitted to GenBank in NCBI with the accession number KY427877, where the Phylogenetic tree of the partial sequence of 16S rDNA of the local isolate (Bacillus sp. MSHN2016) 
with respect to closely related sequences available in GenBank databases was seen in (Fig. 1) So the produced EPS was named EPSMSHN.

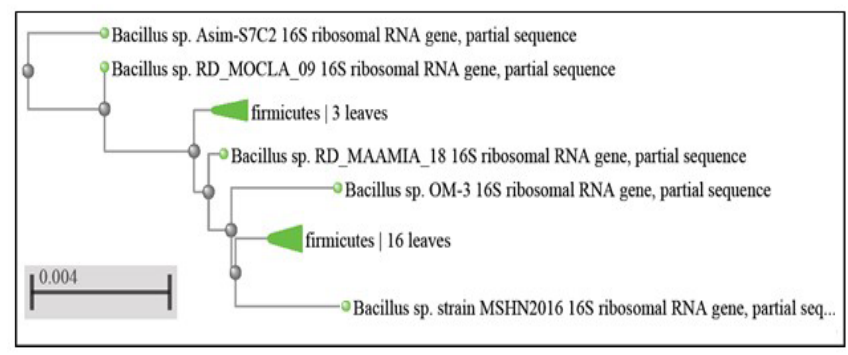

Fig. 1: Phylogenetic tree of the partial sequence of $16 \mathrm{~S}$ rDNA of the local isolate (Bacillus sp. MSHN2016) with respect to closely related sequences available in GenBank databases.

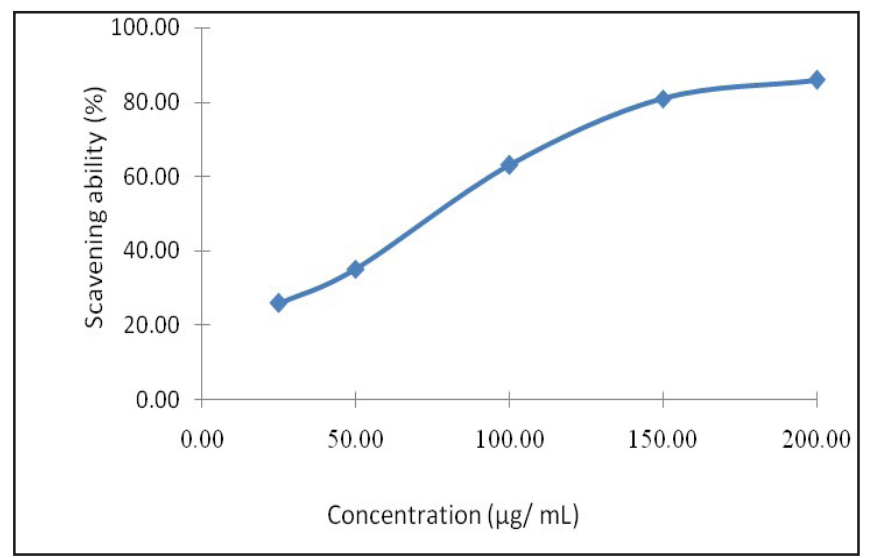

Fig. 2: Scavenging effects of EPSMSHN during DPPH test and measured by changes in absorbance at $517 \mathrm{~nm}$.

\section{Isolation and chemical structure of EPSMSHN}

The maximum yield of EPSMSHN from Bacillus sp. MSHN2016 was $8.25 \mathrm{~g} / \mathrm{L}$ after $96 \mathrm{~h}$. It showed up as a smooth powder, with a negative reaction to the Bradford test. The way that no retention was recognized by the UV spectra at both 260 and 280 $\mathrm{nm}$ showed the nonattendance of protein and additionally nucleic acids. EPSMSHN also contained $14.35 \%$ uronic acid and $18.99 \%$ sulfate. Examination by HPLC demonstrated that EPSMSHN was made out of arabinose, xylose, glucose and glucuronic acid with a relative ratio 1: 1: $2: 1$, respectively. The $(M w)$ and $(M n)$ of EPSMSHN was determined to be $5.50 \times 10^{5}$ and of $3.45 \times$ $10^{5} \mathrm{~g} / \mathrm{mol}$, respectively and $(P I)$ was 1.59 . The FT-IR has been accounted for to be a tool for observing the structural components of polysaccharides. The general appearance of the FT-IR range of EPSMSHN was common of those from polysaccharides. The EPSMSHN contained a significant number of $\mathrm{OH}$ groups, which exhibited an intensive broad stretching peak at around $3437 \mathrm{~cm}^{-1}$. Absorption in $1639 \mathrm{~cm}^{-1}$ revealed the existence of $\mathrm{COO}^{-}$group which may be associated with the glucuronic acid and internal hydrogen bonds. The absorption band at $1420 \mathrm{~cm}^{-1}$ indicated the presence of sulfate ester. The spectrum of the fraction indicates the presence of sulfate group at $1237 \mathrm{~cm}^{-1}$. The absorption at $874 \mathrm{~cm}^{-1}$ indicated the $\alpha$-glycosidic linkages of the fraction.

\section{Antioxidant properties of EPSMSHN}

Natural antioxidants assume principle defensive parts against various infections and maturing forms because of their capacity of scavenging free radicals and binding transition metal ion catalysts and also their reductive action and ability to avert chain start. EPSMSHN exhibited the scavenging activity toward DPPH radicals in a concentration-dependent manner, with an $\mathrm{EC}_{50}$ value of $77 \mu \mathrm{g} / \mathrm{mL}$ (Fig. 2) These outcomes showed that the EPSMSHN noticeably affected scavenging free radical, particularly at high concentration. It is notable that reactive oxygen species (ROS), for example, hydroxyl radicals, superoxide anion, and hydrogen peroxide, are identified with the pathogenesis of different ailments.

\section{Acute toxicity study}

The results exhibited no mortality after $24 \mathrm{~h}$ of oral administration of EPSMSHN in rats of both sex at graded doses up to $4 \mathrm{~g} / \mathrm{kg}$. $1 / 80$ and $1 / 40(50 \& 100 \mathrm{mg} / \mathrm{kg})$ of the maximum dose $(4 \mathrm{~g} / \mathrm{kg})$ were chosen to be used for the pharmacological investigation throughout the study.

\section{Effect on liver-related parameters}

Intraperitoneal injection of INH/RIF $(50 / 100 \mathrm{mg} / \mathrm{kg})$ over a period of 4 weeks significantly $(p<0.05)$ increased all biochemical parameters of liver function as activities of ALT and AST as well as total and direct bilirubin levels compared to the normal control. Treatment with both doses of EPS significantly decreased serum ALT and AST activities as well as total and direct bilirubin levels compared to INH/RIF control. It is worthy to mention that, the effect of EPSMSHN on the hepatotoxicity parameters was nearly similar to that of silymarin (Table 1).

\section{Effect on blood urea nitrogen (BUN) and serum creatinine}

INH/RIF injection induced a significant $(p<0.05)$ increase in BUN level and creatinine level as compared to the normal group indicating kidney injury. Treatment with EPSMSHN could normalize BUN level and reduced serum creatinine level as compared to INH/RIF control. The levels of both BUN and serum creatinine in the EPSMSHN treated groups were lower compared to that of silymarin (Table 2).

Table 1: Effect of polysaccharide on liver parameters.

\begin{tabular}{ccc}
\hline Parameters & ALT (U/L) & ALT (U/L) \\
\hline Normal & $155.79 \pm 0.82^{\mathrm{a}}$ & $181.09 \pm 0.53^{\mathrm{a}}$ \\
INH/RIF & $173.95 \pm 1.37^{*}$ & $222.04 \pm 0.42^{*}$ \\
Silymarin $(25 \mathrm{mg} / \mathrm{kg})$ & $152.55 \pm 1.75^{\mathrm{a}}$ & $206.44 \pm 1.82^{*^{a}}$ \\
EPSMSHN $(50 \mathrm{mg} / \mathrm{kg})$ & $152.15 \pm 2.77^{\mathrm{a}}$ & $211.60 \pm 1.45^{*^{a}}$ \\
EPSMSHN $(100 \mathrm{mg} / \mathrm{kg})$ & $150.59 \pm 2.81^{\mathrm{a}}$ & $202.79 \pm 0.76^{* \mathrm{a}}$ \\
\hline
\end{tabular}

Liver damage was induced by daily injection of INH/RIF (50/100 mg/kg; I.P.) for 4 weeks. Tested agents were orally administered daily for 28 days in concomitant with an injection of INH/RIF. Data were expressed as mean $\pm \mathrm{SE}$ (n $=6$ ). Data were analyzed by one-way ANOVA followed by Tukey comparison test. "vs normal control. a ${ }^{\text {a }}$ INH/RIF control at $\mathrm{p}<0.05$. EPSMSHN: exopolysaccharide; INH/RIF: isoniazide + rifampicin; ALT: alanine aminotransferase; AST: aspartate aminotransferase; BUN: blood urea nitrogen. 
Table 2: Effect of polysaccharide on liver and kidney parameters.

\begin{tabular}{|c|c|c|c|c|}
\hline $\begin{array}{l}\text { Parameters } \\
\text { Groups }\end{array}$ & Total Bilirubin (mg/dl) & Direct Bilirubin (mg/dl) & $\begin{array}{c}\text { BUN } \\
(\mathrm{mg} / \mathrm{dl})\end{array}$ & Creatinine (mg/dl) \\
\hline Normal & $0.51 \pm 0.02^{\mathrm{a}}$ & $0.37 \pm 0.02^{\mathrm{a}}$ & $33.68 \pm 0.61^{\mathrm{a}}$ & $1.23 \pm 0.01^{\mathrm{a}}$ \\
\hline INH/RIF & $1.60 \pm 0.09^{*}$ & $1.17 \pm 0.07 *$ & $38.65 \pm 0.52^{*}$ & $1.71 \pm 0.06^{*}$ \\
\hline Silymarin $(25 \mathrm{mg} / \mathrm{kg})$ & $0.78 \pm 0.04^{* a}$ & $0.57 \pm 0.02^{* a}$ & $36.44 \pm 0.37^{* a}$ & $1.51 \pm 0.05^{*}$ \\
\hline EPSMSHN (50 mg/kg) & $0.97 \pm 0.03^{* a}$ & $0.71 \pm 0.02^{* \mathrm{a}}$ & $33.82 \pm 0.51^{\mathrm{a}}$ & $1.45 \pm 0.07^{\mathrm{a}}$ \\
\hline EPSMSHN (100 mg/kg) & $0.83 \pm 0.03^{* a}$ & $0.61 \pm 0.02^{* a}$ & $34.76 \pm 0.31^{\mathrm{a}}$ & $1.48 \pm 0.07^{*}$ \\
\hline
\end{tabular}

Kidney damage was induced by daily injection of INH/RIF $(50 / 100 \mathrm{mg} / \mathrm{kg}$; I.P.) for 4 weeks. Tested agents were orally administered daily for 28 days in concomitant with an injection of INH/RIF. Data were expressed as mean $\pm \mathrm{SE}(\mathrm{n}=6)$. Data were analyzed by one-way ANOVA followed by Tukey comparison test. " $v s$ normal control. ${ }^{\mathrm{a}} \mathrm{vs}$ INH/RIF control at $\mathrm{p}<0.05$.

\section{Effect on oxidative stress biomarkers}

Hepatic and renal Glutathione (GSH) contents were significantly decreased in rats treated with INH/RIF by about 1.6 and 2.7 folds; respectively. Conversely, the levels of (MDA), which is an index of lipid peroxidation, significantly $(p<0.05)$ increased in the livers and kidneys of rats treated with INH/RIF to about 1.7 and 2.7 folds as compared to the normal group. The study groups treated with EPSMSHN at both doses showed a significant $(\mathrm{p}<0.05)$ increase in INH/RIF-induced hepatic and renal GSH depletion. Furthermore, EPSMSHN prevented INH/RIF-induced lipid peroxidation in liver and kidney tissues. The effect of 100 $\mathrm{mg} / \mathrm{kg}$ EPSMSHN on hepatic and renal MDA contents was better than that of silymarin, the standard hepatoprotective and antioxidant drug (Fig. 3).
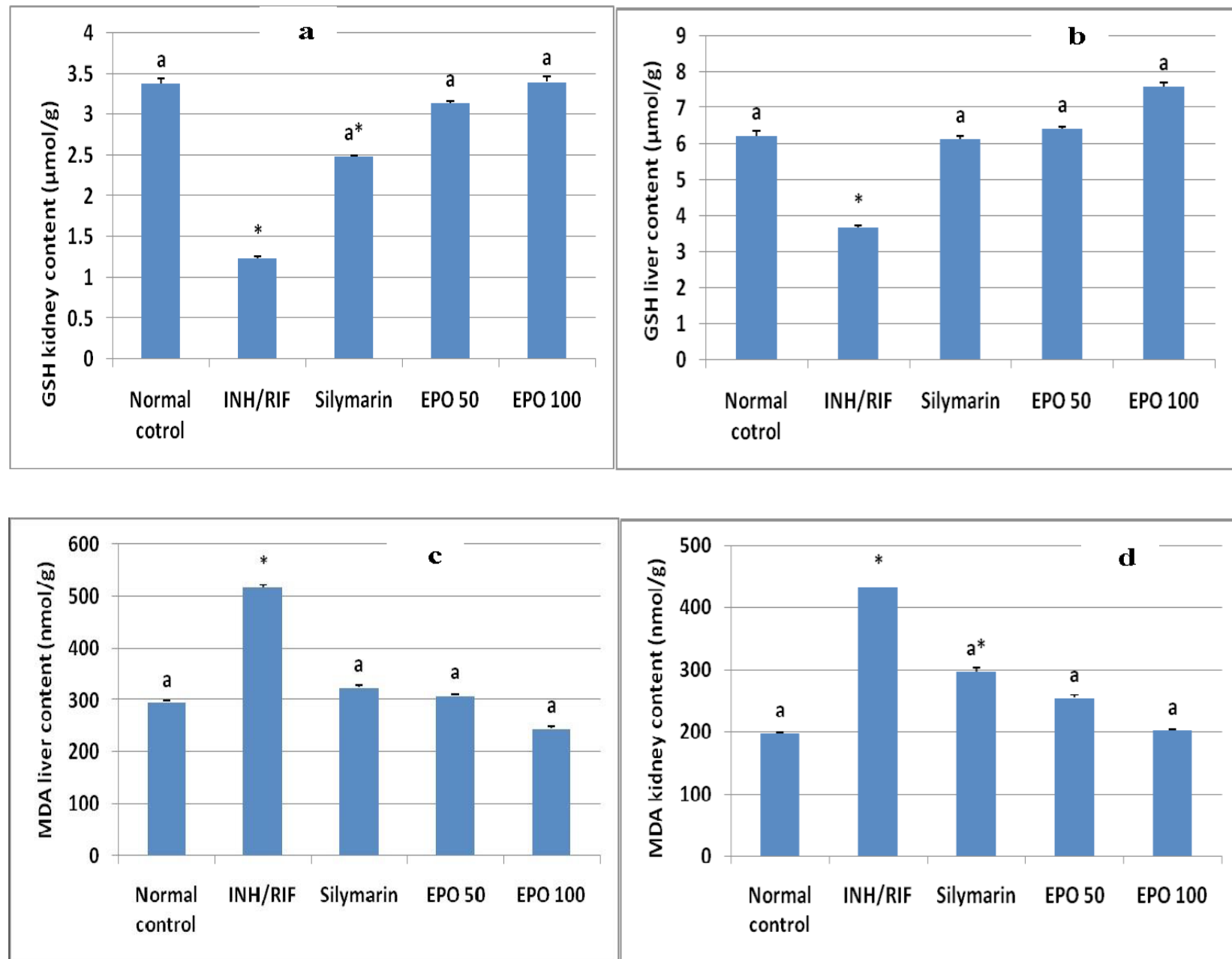

Fig. 3: Effect of EPS on oxidative stress biomarkers (a) hepatic GSH, (b) hepatic MDA (TBARs), (c) renal GSH and (d) renal MDA. Liver and kidney damage was induced by daily injection of INH/RIF (50/100 mg/kg; I.P) for 4 weeks. Tested agents were orally administered daily for 28 days in concomitant with an injection of INH/RIF. Data were expressed as mean $\pm \mathrm{SE}(\mathrm{n}=6)$. Data were analyzed by one-way ANOVA followed by Tukey comparison test. "vs normal control. ${ }^{a} v s \mathrm{INH} / \mathrm{RIF}$ control at $\mathrm{p}<0.05$. EPO: exopolysaccharide; INH/RIF: isoniazide + rifampicin. 


\section{Histopathology of liver tissue and kidney}

Examination of H\&E stained sections from the control group (Normal control) showed the liver to have a normal histological structure of the hepatic tissue showing the normal hepatic architecture inform of hepatic lobules with the average normal thickness of hepatic cords which radiating from centrally located central vein to portal tract peripherally (Fig. 4A), the group which received INH/RIF their hepatic cells has been injured in different forms as ballooning degeneration or apoptosis and some cells appear with pyknotic nuclei most of them losing their cellular wall, Also there is portal tridaitis; inflammatory cells around portal tract with dilated congested hepatic sinusoids (Fig. 4B), On the other hand, the third group which received (silymarin $25 \mathrm{mg} / \mathrm{kg}$ ) has improved in their architecture also the hepatic cells retune their normal features with moderate infiltration of inflammatory cells mainly around the portal tract (Fig. 4C), In the fourth group and fifth group which received EPSMSHN $50 \mathrm{mg}$ / $\mathrm{kg}$ \& EPSMSHN $100 \mathrm{mg} / \mathrm{kg}$ respectively looking to be improved much better than the third group as the hepatic cells mostly retune their cellular lining with minimal inflammatory cells infiltration (Fig. 4D \& E).

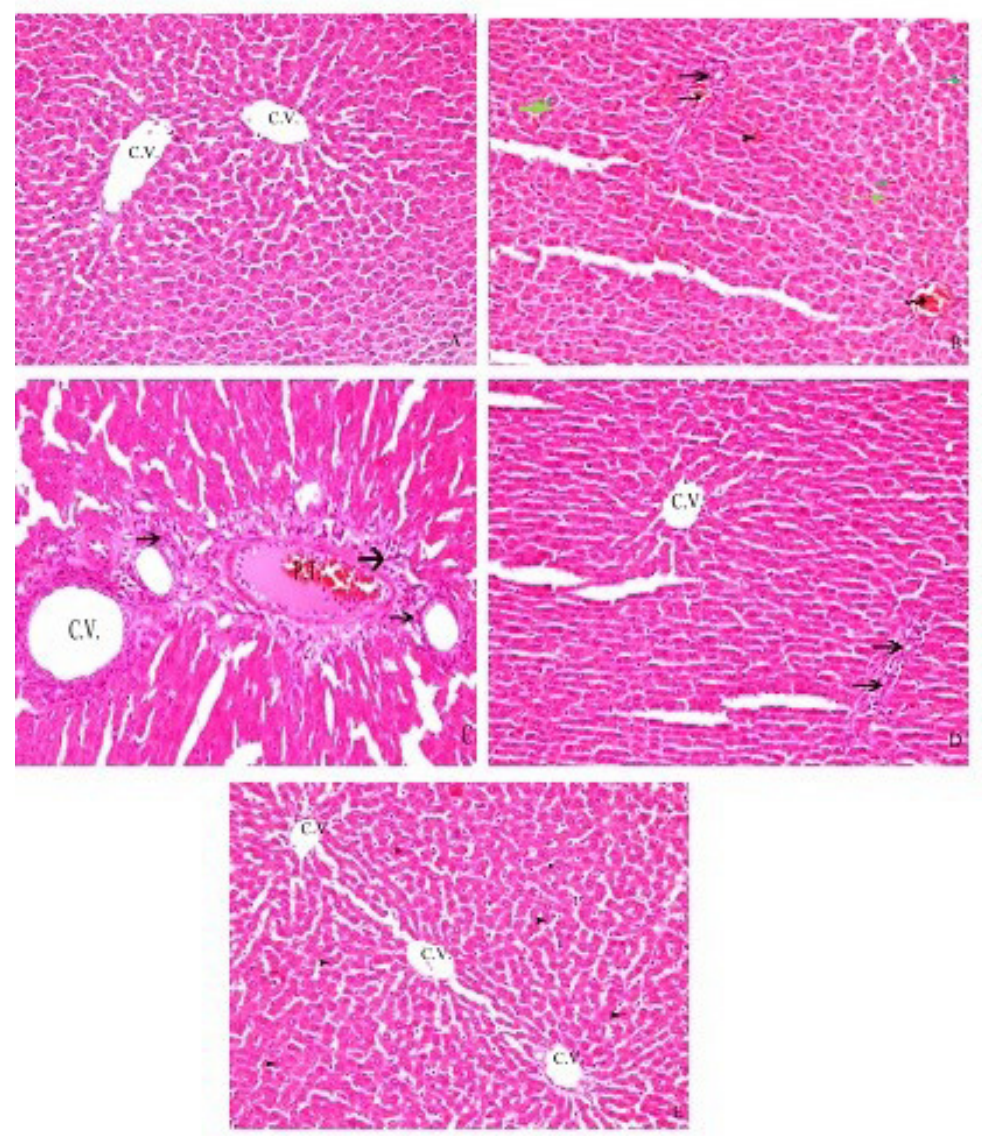

Fig. 4: A photomicrography for five studied groups of the hepatic tissue: (C.V.); Central vein, (P.T.); Portal tract, (Straight Arrow); Inflammatory cells infiltration, (Arrow Head); Dilated congested sinusoids, (Curved Arrow); Thrombichepatic vessels, (Green Arrow) Ballooning degeneration with others showing pyknotic nuclei (H\&E 200). (A): Normal group, (B): INF/RIF, (C): silymarin (25 mg/kg), (D): EPS (50 mg/kg), (E): EPS (100 mg/kg) (Stained Van Gieson X 200).

Examination of H\&E stained sections from the control group (normal control) showed the renal tissue with normally appeared glomeruli and average wall thickness of the tubules lined by well-formed epithelial lining (Fig. 5A), On the other hand, examination of second group INH/RIF showed congested glomerular capillaries with shrunken glomerular tufts some of them have almost lost all their capillaries, the tubules showing edema and shedding of their epithelial lining with sings of degeneration in the form of pyknosis, vacuolation, many of tubules with intratubular debris within congested interstitial tissue and foci of fibrosis (Fig. 5B). The renal tissue of the third group silymarin $25 \mathrm{mg} / \mathrm{kg}$ showing that their glomeruli have evidence of improvement with congestion in the capillary tufts, also the tubules are improved with residual signs of degeneration in the form of intratubular debris within congested interstitial tissue and foci of fibrosis (Fig. 5C), According to the fourth group \& fifth group which treated by EPSMSHN $50 \mathrm{mg} / \mathrm{kg}$ \& EPSMSHN 100 $\mathrm{mg} / \mathrm{kg}$ respectively the renal tissue have the evidence of normal appearance of the glomeruli also the tubules are well improved (Fig. 5D \& E).

\section{Morphometric analysis of liver and kidney tissue}

The fibrosis area percentage and inflammatory cells of liver tissue are significantly increased in all other groups of rats in comparison with control group which were $3.766 \pm 0.20$ and 14.5 \pm 1.027 respectively, on another hand its noticed that the second 
group who taken INF/RIF gives the highest readings; $24.72 \pm$ 0.15 for the fibrotic area $\%$ and $67 \pm 1.107$ for the inflammatory cell count denoting the degree of destruction. The third group which treated by silymarin has significantly decreased from the second group in relation to the inflammatory cell count $30.3 \pm$ 2.80 , while there was non-significant difference in the percentage of the fibrotic area from INF/RIF group; the positive control group $23.303 \pm 1.41$, According to the treated groups by EPSMSHN group 4 and 5; both has highly significant decline in fibrotic area percentages and the counting of inflammatory cells, which were $29.7 \pm 0.42$ for EPS $50 \mathrm{mg} / \mathrm{kg}$ group and $25.4 \pm 0.54$ for EPSMSHN $100 \mathrm{mg} / \mathrm{kg}$ group in comparison with the positive control INF/RIF group also with our reference treatment silymarin group (Fig. 6 \& 7). To be noticed that the fifth group EPSMSHN $100 \mathrm{mg} / \mathrm{kg}$ has better improvement, especially in fibrotic area\% which was 9.063 \pm 0.15 , significant improvement than fourth group EPSMSHN 50 $\mathrm{mg} / \mathrm{kg} 14.02 \pm 0.26$ (Table 3).

Table 3: Morphometric parameters of all studied groups of liver \& kidney tissue.

\begin{tabular}{|c|c|c|c|c|}
\hline \multirow{2}{*}{$\begin{array}{l}\text { Parameters } \\
\text { Groups }\end{array}$} & \multicolumn{2}{|c|}{ Liver tissue } & \multicolumn{2}{|c|}{ Kidney tissue } \\
\hline & Fibrosis area $\%$ & Inf. cells count & Fibrosis area $\%$ & Inf. Cells count \\
\hline Normal & $3.77 \pm 0.20$ & $14.5 \pm 1.027$ & $3.69 \pm 0.62$ & $4.20 \pm 1.03$ \\
\hline INF/RIF & $24.72 \pm 0.15^{*}$ & $67.0 \pm 1.107^{*}$ & $39.23 \pm 1.15^{*}$ & $59.27 \pm 1.14^{*}$ \\
\hline Silymarin $(25 \mathrm{mg} / \mathrm{kg})$ & $23.30 \pm 1.41^{*}$ & $30.3 \pm 2.80^{* a}$ & $32.58 \pm 0.93^{*}$ & $20.2 \pm 0.44^{* a}$ \\
\hline EPSMSHN $(50 \mathrm{mg} / \mathrm{kg})$ & $14.02 \pm 0.26^{* a}$ & $29.7 \pm 0.42^{* a}$ & $17.40 \pm 0.01^{* a}$ & $15.7 \pm 1.88^{* a}$ \\
\hline EPSMSHN $(100 \mathrm{mg} / \mathrm{kg})$ & $9.06 \pm 0.15^{* \mathrm{a}}$ & $25.4 \pm 0.54^{* a}$ & $12.45 \pm 0.86^{* \mathrm{a}}$ & $6.3 \pm 2.62^{* a}$ \\
\hline
\end{tabular}

Data were expressed as mean $\pm \mathrm{SE}(\mathrm{n}=6)$. Data were analyzed by one-way ANOVA. ${ }^{*} v s$ Normal Control. ${ }^{a} v s$ INH/RIF Control at $\mathrm{p}<0.05$. EPSMSHN: exopolysaccharide; INH/RIF: isoniazide + rifampicin.

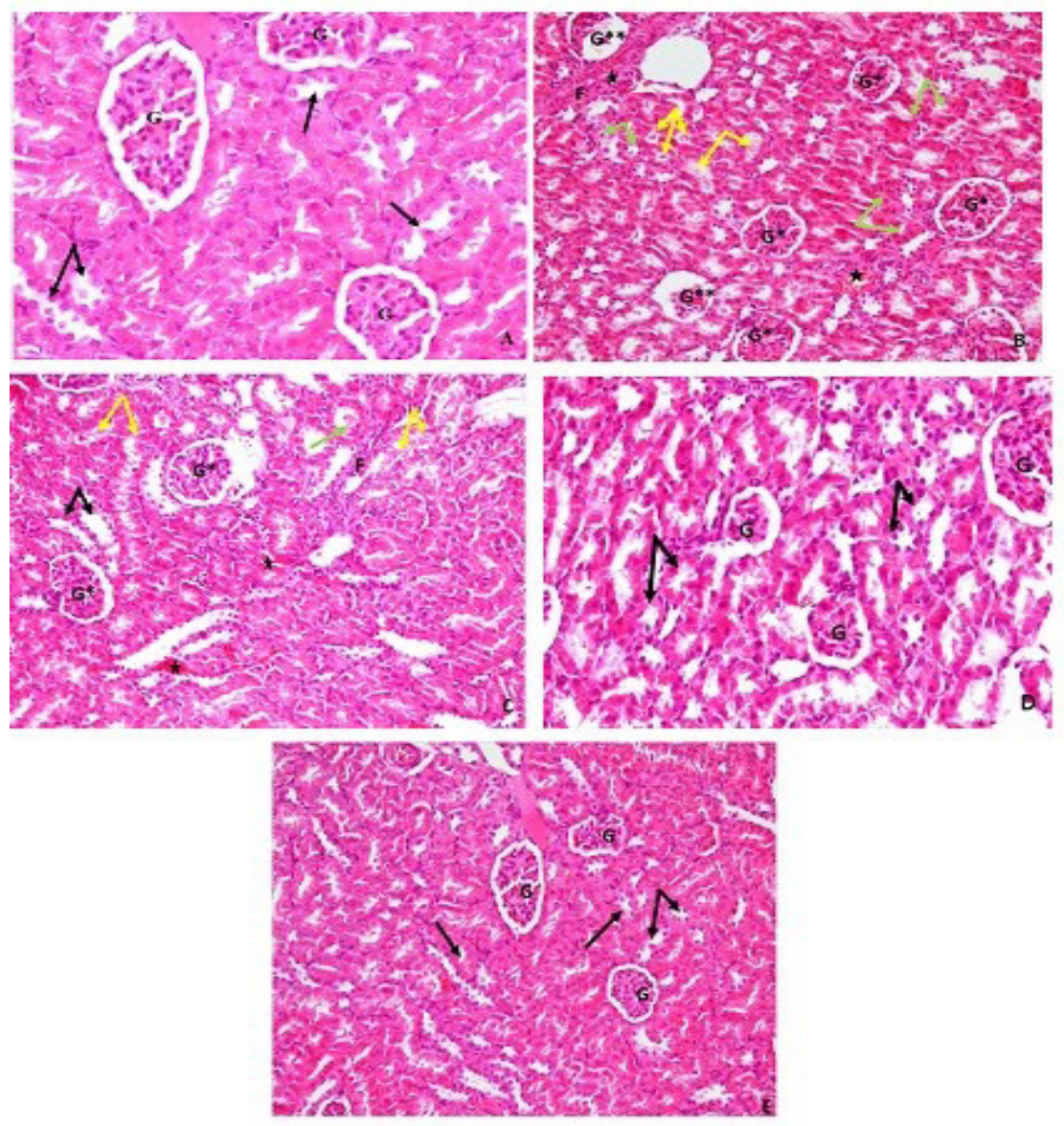

Fig. 5: A photomicrography for five studied groups of the renal tissue: $(G)$; Normal appeared glomeruli, $\left(G^{*}\right)$; Congested glomeruli capillaries, $\left(G^{* *}\right)$; Glomeruli capillaries mostly are lost, (Black Arrow); Normal appearance of tubules, (Yellow Arrow); Tubules with edematous shedded) epithelial lining, (Green Arrow); Intratubular debris, (F); fibrosis, (Black Star); Congestion in interstitial tissue (H\& E200). (A): Normal group, (B): INF/RIF, (C): Silymarin (25 mg/kg), (D): EPS (50 $\mathrm{mg} / \mathrm{kg}$ ), (E): EPS (100 mg/kg) (Stained Van Gieson X 200). 

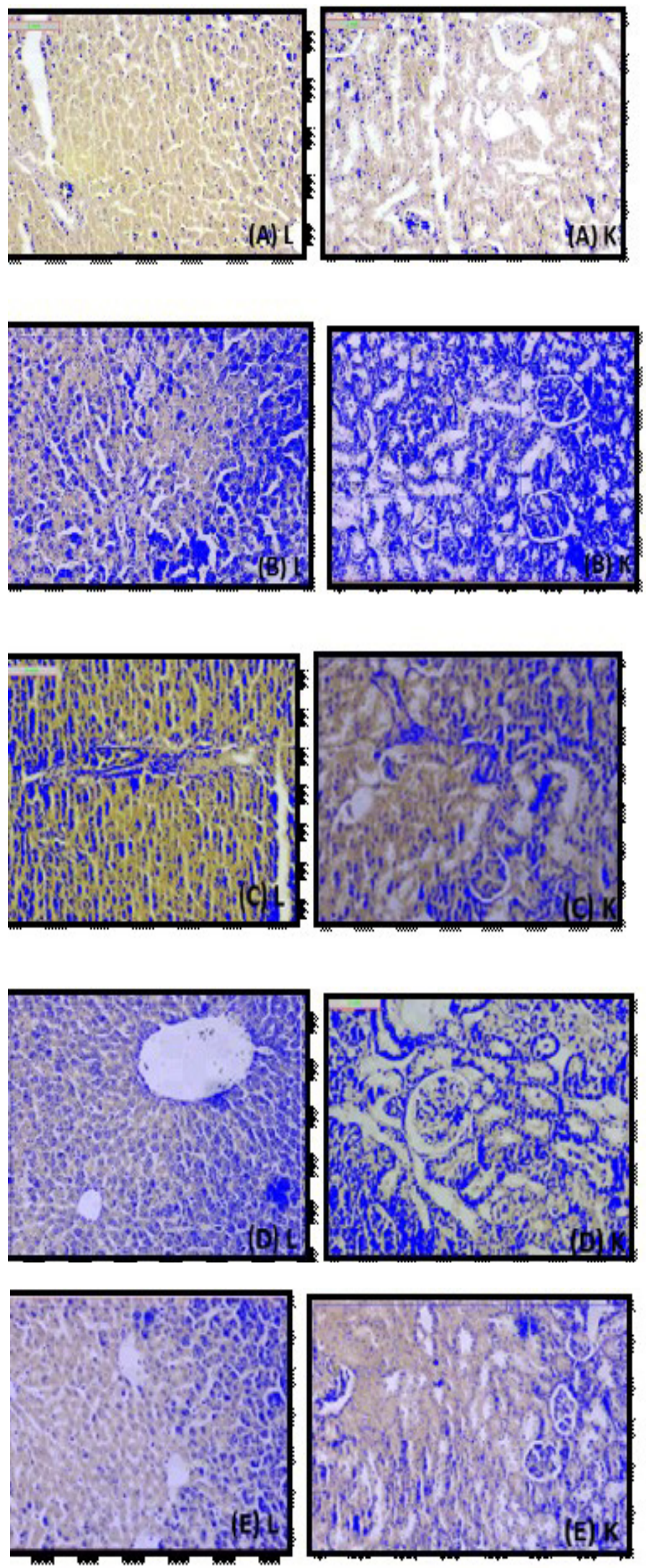

Fig. 6: The print screens of the morphometric measurement of fibrotic area in all studied groups of both liver and kidney tissue. L: Liver tissue, K: Kidney tissue, (A): Normal group, (B): INF/RIF, (C): silymarin (25 mg/kg), (D): EPS (50 mg/kg), (E): EPS (100 mg/kg) (Stained Van Gieson X 200). 

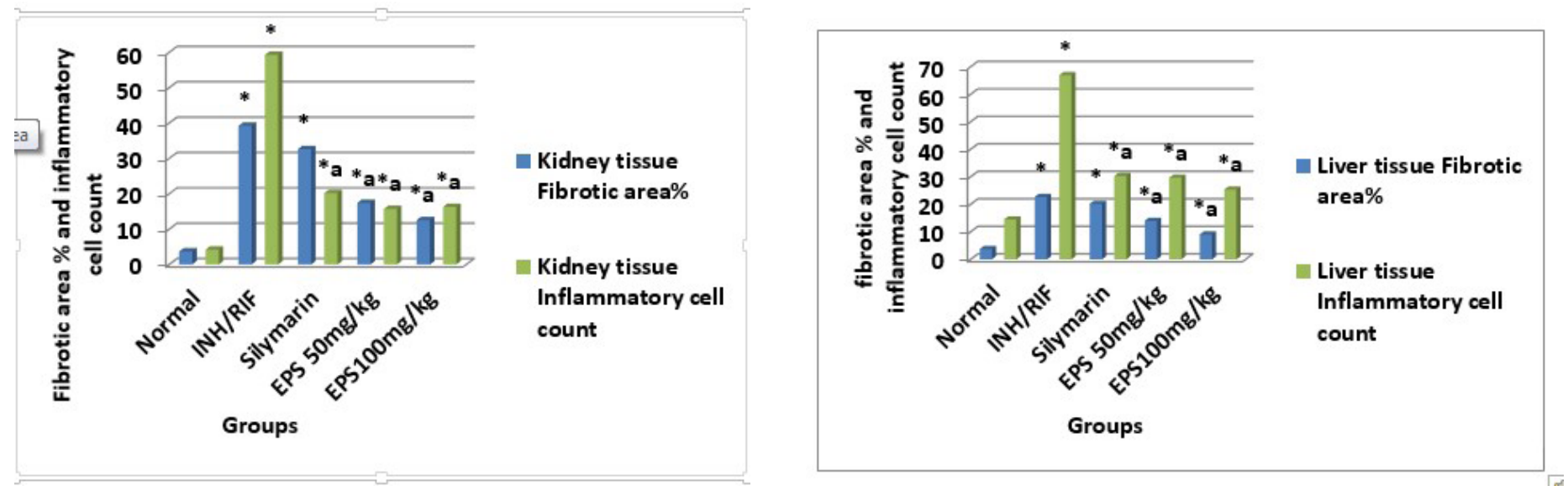

Fig. 7: Fibrotic area $\%$ and inflammatory cell count in all tested groups in kidney and liver tissue. Data were expressed as mean $\pm \mathrm{SE}(\mathrm{n}=6) .{ }^{*} v S$ normal control. ${ }^{a} v S$ INH/RIF control at $\mathrm{p}<0.05$. EPS: exopolysaccharide; INH/RIF: isoniazide + rifampicin.

According to the fibrosis area percentage and inflammatory cell count of kidney tissue the control negative group were $3.697 \pm 0.62$ and $4.2 \pm 1.03$ respectively which were significantly decreased than all other four groups (Fig. $6 \& 7$ ), While the second group which received INF/RIF gives the highest readings; in both parameters; $39.23 \pm 1.15$ for fibrotic area percent and $59.27 \pm 1.14$ for the inflammatory cell count. The third group treated by silymarin has significantly decreased from the second group in relation to the inflammatory cell count $20.2 \pm 0.44$ while there was non-significant difference in the percentage of the fibrotic area $32.58 \pm 0.93$ from the positive control INF/RIF group (Table 3), According to the treated groups by polysaccharides group 4 and 5; both have a high significant decline in fibrotic area $\% 17.40 \pm 0.01$ and $12.45 \pm 0.86$, respectively also it happened in the counting of inflammatory cells $15.7 \pm 1.88$ for fourth group EPSMSHN $50 \mathrm{mg} / \mathrm{kg}$ and $6.3 \pm 2.62$ for the fifth group EPSMSHN $100 \mathrm{mg} / \mathrm{kg}$ in comparison with the positive control INF/RIF group also with our reference treatment silymarin group.

\section{DISCUSSION}

In present work the isolated Bacillus sp. MSHN2016 produced EPSMSHN with a very good yield, also EPSMSHN is contained functional groups like $\mathrm{SO}_{3}^{-}$and $\mathrm{COO}^{-}$. The $\mathrm{Mw}$ of EPSMSHN was $5.50 \times 10^{5} \mathrm{~g} / \mathrm{mol}$. All the previous results indicate the protective role of EPSMSHN against INH/RFP-induced hepatic and renal toxicity. It was found by many authors that marine bacteria consider very good sources of EPSs if compared with the terrestrial sources (Jensen and Fenical, 1994; Laurienzo, 2010). The majority of EPSs produced by marine bacteria are heteropolysaccharides where the hydrolysis of the EPSMSHN by HPLC indicates the presence of four different monosaccharides, while monosaccharides of EPS from marine Bacillus subtilus were five (Ghoneim et al., 2016).

EPSMSHN is also contained different functional groups like $\mathrm{SO}_{3}^{-}$and $\mathrm{COO}^{-}$. The percentage of sulfate and uronic differ from EPS to another wherein marine Bacillus subtilus the percentage of $\mathrm{SO}_{3}^{-}$was lower than that found in EPSMSHN, while the uroinc was higher in case of Bacillus subtilus due to the different origin of both organisms (Casillo et al., 2018). Some EPS are neutral macromolecules, yet the larger parts are polyanionic because of the nearness of uronic acids or ketalconnected pyruvate or inorganic residues, like $\mathrm{PO}_{4}^{-}$and/or $\mathrm{SO}_{3}^{-}$ (Zhang et al., 2016).

It was mentioned that most polymers are linear, with an average $M w$ ranging from $1 \times 10^{5}$ to $3 \times 10^{5} \mathrm{Da}$ (Casillo et al., 2018). The physical properties of polysaccharides are influenced by the way and aggregation the monosaccharides. The biological activities of the EPSs based on the chemical structure and the molecular weight (Laurienzo, 2010).

Albeit many known marine bacteria can deliver EPSs, few them are of biotechnological significance (Zhang et al., 2016; Kichemazova et al., 2017).

So, in the current study, EPSMSHN could ameliorate liver and kidney damage induced by INH and RIF by decreasing serum levels of ALT, AST, total and direct bilirubin, BUN and creatinine. Hepatotoxicity arises from long-term and clinical use of INH or RIF in (TB) treatment (Nanashima et al., 2012), different metabolic and morphologic aberrations were detected after administration because of their detoxification in liver (Santhosh et al., 2007). INH/RIF combination has been evolved as an experimental model of hepatic injury. Metabolism of INH occurs through acetylation and hydrolysis and the acetylated metabolites are hepatotoxins (Steele et al., 1991). Hydrazine metabolite induces cytochrome P450 (CYP450) and promotes the production of more hepatotoxins (Vuilleumier et al., 2006). Several studies have proven that RIF elevates INH toxic metabolite (hydrazine) formation. Inhibition of biliary secretion, as well as lipid peroxidation in the liver tissue, is aggravated by this combination (Zhang et al., 2012). In the present study, INH and RIF injection produced signs of hepatotoxicity as indicated by increased ALT, AST, total and direct bilirubin. These findings are in accordance with previous data (Santhosh et al., 2006; Obogwu et al., 2014; Kim et al., 2017).

INH/RIF combination also elevated renal function tests, BUN and serum creatinine. Experimental nephrotoxicity was not previously documented except in the study by Hashmi et al. (2013), who found that INH/RIF induced significant renal damage to rabbits as evidenced by elevated concentrations of the BUN and serum creatinine. Renal toxicity of RIF has been reported sporadically, however, some authors have reported clinical cases 
occurring during continuous RIF therapy (Muthukumar et al., 2002; Yanardag et al., 2005). Oxidative stress has been implicated in the INH/RIF hepatotoxic effect (Cederbaum, 2006) via endogenous lipids peroxidation with the subsequent cell membrane destruction (Santhosh et al., 2007). In the current study, the combined anti TB drugs increased lipid peroxidation and decreased GSH (the endogenous antioxidant) contents in the liver, this is in agreement with other results (Tasduq et al., 2005; Saad et al., 2010), and for the first time in kidney tissues.

Treatment with EPSMSHN prevented the incidence of hepatocellular apoptosis and degeneration and fibrosis in many tubules also promoted tissue recovery due to liver and kidney injury. Li et al. (2006) studied the mechanism of polysaccharides from Cordyceps sp. resistance on dimethyl-induced liver fibrosis through elevation of liver Kupffer cell function, toxic substances removal as well as reducing the immune and inflammatory response (Fang et al., 1997).

Bioactivities of EPSs were found to be ascribed to their individual structure, such as the type of glycosyl units, the configuration of glycosidic bonds, and the substituent of the EPSs. Also, these biological effects are closely related to the spatial structure and molecular weight (Tsiapali et al., 2001). Therefore, the anti-oxidative activity of the EPS may not be a result of a single factor, but a combination of different factors, most importantly variation in monosaccharide composition, structure configuration, and mode of attending glycosidic bonds and other structural characteristics of the EPS (Moure et al., 2006).

In the present work, EPSMSHN could ameliorate liver and kidney lipid peroxidation and increased GSH contents induced by INH and RIF. In addition, EPSMSHN could attenuate liver inflammation and kidney fibrosis as shown in our histopathological study compared to the control group and better than silymarin.

\section{CONCLUSION}

EPSMSHN produced from marine Bacillus sp. MSHN2016 at both doses protected from hepatic and renal toxicity induced by INH/RFP through its antioxidant and antifibrotic influence; therefore, it can be used as neutraceutical for treatment of hepatic and renal diseases.

\section{CONFLICT OF INTEREST}

None declared.

\section{REFERENCES}

Al-Nahas MO, Darwish MM, Ali AE, Amin MA. Characterization of an exopolysaccharide-producing marine bacterium, isolate Pseudoalteromonas sp. AM. Afr J Microbiol Res, 2011; 5(22):38233831.

Asker MM, Shawky BT. Structural characterization and antioxidant activity of an extracellular polysaccharide isolated from Brevibacterium otitidis BTS44. Food Chem, 2010; 123:315-320.

Bancroft JD, Gamble M. 2008. Hematoxlyin and eosin, connective tissue and stain, carbohydrates, Chapters 9-11. In: Theory and practice in histological techniques. $6^{\text {th }}$ ed. Philadelphia, PA: Churchill Livingstone/ Elsevier, 121-186.

Cappuccino JG, Sherman N. 2004. Microbiology laboratory manual. Pearson Education Inc. New Delhi.

Casillo C, Lanzetta R, Parrilli M, Corsaro M. Exopolysaccharides from marine and marine extremophilic bacteria: structures, properties, ecological roles and applications. Mar Drugs, 2018; 16:1-34.
Cederbaum AI. Cytochrome P450 2E1-dependent oxidant stress and upregulation of anti-oxidant defense in liver cells. J Gastroenterol Hepatol, 2006; 21:S22-S25.

Chen X, Xu J, Zhang C, Yu T, Wang H. The protective effects of ursodeoxycholic acid on isoniazid plus rifampicin induced liver injury in mice. Eur J Pharmacol, 2012; 659:53-60.

Desoukey SY, El Kady WM, Salama AAA, Hagag EG, ElShenawy SM, El-Shanawany MA. Hepatoprotection and antioxidant activity of Gazania longiscapa and G. rigens with the isolation and quantitative analysis of bioactive metabolites. Int J Pharmacogn and Phytochem Res, 2016; 8(7):1121-1131.

Dodgson KS, Price RG. A note on the determination of the ester sulfate content of sulfated polysaccharides. Biochem J, 1962; 84:106-110.

Ellman GL. Tissue sulfhydryl groups. Arch Biochem Biophys, $1959 ; 82: 70-77$.

El-Sayed OH, Ismail SA, Ahmed YM, Abd El-Samei M, Asker MM. Studies on the production of sulfated polysaccharide by locally isolated bacteria. Egypt Pharm J, 2007; 4:439-452.

Fang BW, Liu P, Xu LM, Li FH, Gu HT, Wang HN, Hu YY, Liu C. The effect of cordyceps polysaccharides on liver fibrosis induced by BSA. Chin. J Tradit Med Sci Tech, 1997; 4:103-105.

Filisetti-Cozzi, TMC, Carpita C. Measurement of uronic acids without interference from neutral sugars. Anal Biochem, 1991; 197:157162.

Ghoneim MA, Hassan AI, Mahmoud MG, Asker MS, Effect of polysaccharide from Bacillus subtilis sp. on cardiovascular diseases and atherogenic indices in diabetic rats. BMC Complement Alternat Med, 2016; $16: 1-12$.

Hashmi N, Muhammad F, Javed I, Khan JA, Muhammad MZ, Khaliq T, Aslam B. Nephroprotective effects of Ficus religiosa Linn. (Peepal) stem bark against isoniazid and rifampicin induced nephrotoxicity in albino rabbits. Pak Vet J, 2013; 33(3):330-334.

Hayakawa M, Nonomura H. Vitamin agar, a new medium for the selective isolation of soil actinomycetes. J Ferment Technol, 1987; 65:501509 .

Jensen PR, Fenical W. Strategies for the discovery of secondary metabolites from marine bacteria: Ecological perspectives. Annu Rev Microbiol, 1994; 48:559-584.

Jun HI, Lee H, Song GS, Kim YS. Characterization of the pectic polysaccharide from pumpkin peel. LWT - Food Sci Technol, 2006; 39:554556. 38:S44-S48.

Kaplowitz N. Drug induced liver injury. Clin Infect Dis, 2004;

Kaplowitz N. Drug-induced liver disorders: implications for drug development and regulation. Drug Safety, 2001; 24:483-490.

Kichemazova NV, Bukharova EN, Selivanov NY, Bukharova IA, Karpunina LV. Preparation, properties and potential applications of exopolysaccharides from bacteria of the genera Xanthobacter and Ancylobater. Appl Biochem Microbiol, 2017; 53:325-330.

Kim JH, Nam WS, Kim SJ, Kwon OK, Seung EJ, Jo JJ, Shresha R, Lee TH, Jeon TW, Ki SH, Lee S. Mechanism investigation of rifampicininduced liver injury using comparative toxicoproteomics in Mice. Int J Mol Sci, 2017; 18(7):1417-1427.

Laurienzo P. Marine polysaccharides in pharmaceutical applications: an overview. Mar Drugs, 2010; 8:2435-2465.

Li FH, Liu P, Xiong WG, Xu WF. Effects of cordyceps polysaccharide on liver fibrosis induced by DMN in rats. China J Chin Mater Med, 2006; 31:1968-1971.

Moure A, Dominguez H, Parajo JC. Antioxidant properties of ultrafiltration-recovered soy protein fractions from industrial effluents and their hydrolysates. Process Biochem, 2006; 41:447-456.

Muthukumar T, Jayakumar M, Fernando EM, Muthusethupathi MA. Acute renal failure due to rifampicin: a study of 25 patients. Am J Kidney Dis, 2002; 40(4):690-696.

Nanashima K, Mawatari T, Tahara N, Higuchi N, Nakaura A. Genetic variants in antioxidant pathway: risk factors for hepatotoxicity in 
tuberculosis patients. Tuberculosis. 2012; 92:253-259.

Obogwu MB, Akindele AJ, Adeyemi OO. Hepatoprotective and in vivo antioxidant activities of the hydroethanolic leaf extract of Mucuna pruriens (Fabaceae) in antitubercular drugs and alcohol models. Chin J Nat Med, 2014; 12(4):273-283.

Ohkawa H, Ohishi N, Yagi K, Assay for lipid peroxides in animal tissues by thiobarbituric acid reaction. Anal Biochem, 1979; 95:351-358.

Pessayre D, Berson A, Fromenty B, Mansouri A. Mitochondria in steatohepatitis. Semin Liver Dis, 2001; 21:57-69.

Ray B. Polysaccharides from Enteromorpha campressa: isolation, purification and structural features. Carbohydr Polym, 2006; 66:408-416

Reed JC. Apoptosis-regulating proteins as targets for drug discovery. Trends Mol Med, 2001; 7:314-319.

Robin MA, Le Roy M, Descatoire V, Pessayre D. Plasma membrane cytochromes-P450 as neoantigens and autoimmune targets in drug-induced hepatitis. J Hepatol, 1997; 26:23-30.

Saad EI, El-Gowilly SM, Sherhaa MO, Bistawroos AE. Role of oxidative stress and nitric oxide in the protective effects of $\alpha$-lipoic acid and aminoguanidine against isoniazid-rifampicin-induced hepatotoxicity in rats. Food Chem Toxicol, 2010; 48:1869-1875.

Santhosh S, Sini TK, Anandan R, Mathew PT. Effect of chitosan supplementation on antitubercular drugs-induced hepatotoxicity in rats. Toxicology, 2006; 219:53-59.

Santhosh S, Sini TK, Anandan R, Mathee PT. Hepatoprotective activity of chitosan against isoniazid and rifampicin-induced toxicity in experimental rats. Eur J Pharmacol, 2007; 572:69-73.

Selim MS, Amer SK, Mohamed SS, Mounier MM, Rifaat HM. Production and characterisation of exopolysaccharide from Streptomyces carpaticus isolated from marine sediments in Egypt and its effect on breast and colon cell lines. J Genet Engin Biotechnol, 2018; 16:23-28.

Sharma SK. Antituberculosis drugs and hepatotoxicity. Infect Genet Evol, 2004; 4:167-170.

Shene C, Canquil S, Rubilar M. Production of the exopolysaccharides by Streptococcus thermophilus: effect of growth conditions on fermentation kinetics and intrinsic viscosity. Int J Food Microbiol, 2008; 124(3):279-284.

Shih TY, Young TH, Lee HS, Hsieh CB, Hu OY. Protective effects of kaempferol on isoniazid- and rifampicin-induced hepatotoxicity. AAPS J, 2013; 15(3):753-762.

Steele MA, Burk RF, Des Prez RM. Toxic hepatitis with isoniazid and rifampicin: A meta-analysis. Chest, 1991; 99:465-471.

Sudhamani, SR, Tharanathan RN, Prasad MS. Isolation and characterization of an extracellular polysaccharide from Pseudomonas caryophylli CFR 1705. Carbohydr Polym, 2004; 56:423-427.

Tamura K, Dudley J, Nei M, Kumar S. Molecular Evolutionary Genetics Analysis (MEGA) software version 4.0. Mol Biol Evol, 2007; 24:1596-1599.

Tasduq SA, Peerzada K, Koul S, Bhat R, Johri RK, Biochemical manifestations of anti-tuberculosis drugs induced hepatotoxicity and the effect of silymarin. Heptol Res, 2005; 31: 132-135.

Trauner M, Meier PJ, Boyer JL. Molecular pathogenesis of cholestasis. New Engl J Med, 1998; 339:1217-1227.

Tsiapali E, Whaley S, Kalbfleisch J, Ensley HE, Browder IW, Williams DL, Glucans exhibit weak antioxidant activity, but stimulate macrophage free radical activity. Free Radical Biol Medic, 2001; 30:393402 .

Vuilleumier N, Rossier MF, Chiappe A, Degoumois F, Dayer P, Mermillod B, Nicod L, Desmeules J, Hochstrasser D. CYP2E1 genotype and isoniazid-induced hepatotoxicity in patients treated for latent tuberculosis. Eur J Clin Pharmacol, 2006; 62:423-429.

Weisburg WG, Barns SM, Pelletier DA, Lane DJ. 16S ribosomal DNA amplification for phylogenetic study. J Bacteriol, 1991; 173:697-703.

Yamamoto T, Kikkawa R, Yamada H, Horii I, Identification of oxidative stress-related proteins for predictive screening of hepatotoxicity using a proteomic approach. J Toxicol Sci, 2005; 30(3):213-227.

Yanardag H, Caner M, Gunes Y, Uygun S, Acutehemolysis and oligoanuric acute renal failure caused by interrupted. Internet J Nephrol, 2005; 2(1):1-3.

Ye S, Liu F, Wang J, Wang H, Zhang M. Antioxidant activities of an exopolysaccharide isolated and purified from marine Pseudomonas PF-6. Carbohydr Polym, 2012; 87:764-770.

You L, Gao Q, Feng M, Yang B, Ren J, Gu L, Cui C, Zhao M. Structural characterization of polysaccharides from Tricholoma matsutake and their antioxidant and antitumour activities. Food Chem, 2013; 138:2242-2249.

Yun $\mathrm{CH}$, Okerholm RA, Guengerich FP. Oxidation of the antihistaminic drug terfenadine in human liver microsomes: role of cytochrome P-450 3A(4) in N-dealkylation and C- hydroxylation. Drug Metab Dispos, 1993; 21:403-409.

Zhang Y, Zhou T, Wang H, Cui Z, Cheng F, Wang KP. Structural characterization and in vitro antitumor activity of an acidic polysaccharide from Angelica sinensis (Oliv.) Diels. Carbohydr Polym, 2016; 20:147-144.

Zhang ZH, Tang JH, Zhan ZL, Zhang XL, Wu HH. Cellular toxicity of isoniazid together with rifampicin and the metabolites of isoniazid on QSG-7701 hepatocytes. Asian Pac J Trop Med, 2012; 5:306309.

How to cite this article:

Selim MS, Mohamed SS, Asker MM, Salama AAA, Abdullah HMI, Yassen NN. Production and characterization of exopolysaccharide from marine Bacillus sp. MSHN2016 with studying its effect on isoniazid/rifampicin-induced hepatic and renal toxicities in rats. J App Pharm Sci, 2018; 8(08): 001-011. 